\title{
Señderos
}

\section{Relaciones entre la didáctica en educación inicial y la cultura ${ }^{1}$}

\author{
Relations between teaching in early education and culture
}

\section{Autora: \\ Rosa Julia Guzmán Rodríguez ${ }^{2}$}

\section{Introducción}

Puede sorprender el título de este documento, porque con frecuencia se tiende a considerar que, en la educación inicial la didáctica no tiene cabida y aún menos se considera que la infancia sea una etapa de la vida en la que en las aulas $^{1}$ se puedan establecer relaciones con la cultura.

Sin embargo, la relación entre la educación inicial y la cultura está dada desde sus orígenes, porque los niños ${ }^{2}$ que ingresan a la educación inicial hacen parte de una cultura, que contribuye a la construcción de lo que sucede en el aula a través de creencias, valores, hábitos, costumbres y lenguajes, entre otros aspectos que determinan aportes y necesidades específicas en los niños y que los educadores necesitan tomar en cuenta para adelantar su labor.

Por otra parte, si se habla de educación inicial necesitamos reconocer que estamos hablando de un proceso de aprendizajes de diferentes órdenes, para los que se requieren didácticas específicas 
“a fin de evitar que estos niveles se conviertan en lugares de cuidado, sin ningún propósito de aprendizaje y de desarrollo” (Guzmán, Ghitis y Ruiz, 2018, p. 129).

La educación inicial en su conjunto aún no ha asumido —o no la han dejado hacerlo-, el salir de la mirada "infantil" sobre ella, que la circunscribe a liviandades y no a cuestionarse cómo es su discurso y su hacer en los tiempos histórico-político-socioculturales actuales. (Peralta, 2017, p. 24)

Lo anterior nos hace pensar en situaciones que se presentan cotidianamente en las instituciones de educación inicial, en las que se oyen discusiones acerca de los mejores materiales para los niños, aduciendo que estos serán útiles para desarrollar tal o cual habilidad, sin que esta decisión esté sustentada en una perspectiva didáctica. Es así como fácilmente se puede caer en el uso de técnicas, a través de las cuales no se buscan un desarrollo y un aprendizaje articulados. Si bien las discusiones sobre los materiales son importantes, en sí mismas no agotan el análisis de las necesidades de los niños. La educación inicial requiere análisis de fondo, que le otorgue sentido dentro de cada cultura en particular.

Otro tanto sucede con el diseño de actividades para desarrollar en el aula, que se presentan como llamativas para los niños. Sin embargo,

Es muy diferente entretener a los niños con actividades "lúdicas" que despertar su interés y entusiasmo a lo largo del proceso de enseñanza, gracias a que la estrategia seleccionada es adecuada para el objetivo propuesto y responde a las necesidades e intereses de los niños". (Guzmán et al., 2018. p. 98)

En este documento nos centraremos en el campo específico de la didáctica de la alfabetización inicial.

\section{¿Por qué es importante pensar en la alfabetización inicial en este nivel?}

En primera instancia es necesario aclarar que en este nivel la expectativa no es que los niños aprendan a escribir convencionalmente, pero también es necesario aclarar que no existe ninguna razón para evitar que los niños se relacionen con las letras, como desafortunadamente sucede en muchos jardines infantiles, a pesar de que uno de los principios rectores de la educación inicial es la literatura y en la Estrategia de Cero a siempre se plantea: "Ello no significa sin embargo, desconocer las escrituras iniciales de las que se valen las niñas y los niños para plasmar sus historias, los descubrimientos sobre la lengua escrita que hacen, sus incesantes preguntas — "aquí qué dice-" (MEN, 2014, p. 24).

Por otra parte, es importante tener en cuenta una afirmación de Emilia Ferreiro (2010), refiriéndose a la pregunta de si a los niños hay que enseñarles a leer y a escribir en preescolar o en primer grado: "Esa es una pregunta mal planteada, porque los niños tienen la mala costumbre de no pedir permiso para aprender". La afirmación anterior 
se refiere a los aprendizajes que hacen los niños de manera espontánea, por el hecho de participar de una cultura letrada. A este proceso se le reconoce como "alfabetismo emergente", entendido como "el surgimiento de comportamientos alfabéticos durante el camino temprano o inicial que los niños y las niñas recorren para llegar a ser lectores y escritores competentes. Estas evidencias tempranas revelan ciertos conocimientos relacionados con los dominios involucrados en el aprendizaje inicial de la lectura y la escritura" (Flórez, Restrepo y Schwanenflugel, 2007, p. 17).

Frank Smith (1983) reconoce este aspecto como información no visual. Este autor señala que la lectura es un proceso que se lleva a cabo con el cerebro y no con los ojos; estos son solamente el canal por el que entra la información (para el caso de las personas videntes). Afirma que en el proceso de lectura entran en juego la información visual, constituida por los signos impresos, y la información no visual, que se refiere al conocimiento del mundo, del tema que leemos, de la lengua, etc. Mientras más información no visual tengamos, menos información no visual requerimos y viceversa. Dicho lo anterior, podemos sintetizar la importancia de pensar la alfabetización inicial con los niños más pequeños, enfatizando en que no tiene sentido que estando en un medio letrado, el único lugar en que los niños no puedan entrar en contacto con las letras, sea el jardín infantil o los centros de desarrollo. Lo importante es pensar cómo hacerlo de manera que podamos aprovechar los conocimientos que los niños traen del medio para ayudarlos a avanzar en ellos sin presionarlos y sin caer ni en aprendizajes académicos del nivel de primeria ni en aprendizajes estereotipados basados en planas y copias que ya se sabe que producen efectos adversos.

\section{¿Cómo enfocar una didáctica que facilite la alfabetización inicial en los niños pequeños?}

Para lograr una didáctica que facilite la alfabetización inicial en los niños pequeños es necesario precisar a qué nos referimos. Entendemos por facilitación de la alfabetización inicial "el acercamiento de los niños a los usos sociales de la lectura y la escritura y al desarrollo de la oralidad” (Guzmán y Guevara, 2013, p. 863). Es decir que se busca continuar en las instituciones del nivel inicial con el proceso que los niños adelantan en un medio letrado de manera natural, también conocido como alfabetismo emergente.

Cualquier persona que haya interactuado con niños pequeños habrá visto cómo ellos preguntan constantemente: ¿qué dice ahí?, ¿cómo se escribe tal cosa?, ¿esta es mi letra?, ¿esta es la letra de mamá?, entre muchas otras preguntas. Habrá visto también que empiezan a reconocer los nombres de los almacenes y otros establecimientos, así como de los productos que consumen, por los logos que tienen. Asimismo, los habrá visto con sus intentos de escritura haciendo rayones, palos, bolas y otros trazos con intención comunicativa. A todos estos intentos les subyace una lógica diferente a la del adulto, porque los niños plantean hipótesis sobre la escritura, como ya lo demostraron Ferreiro y Teberosky (1989) con sus investigaciones, como en los ejemplos que se muestran a continuación. 


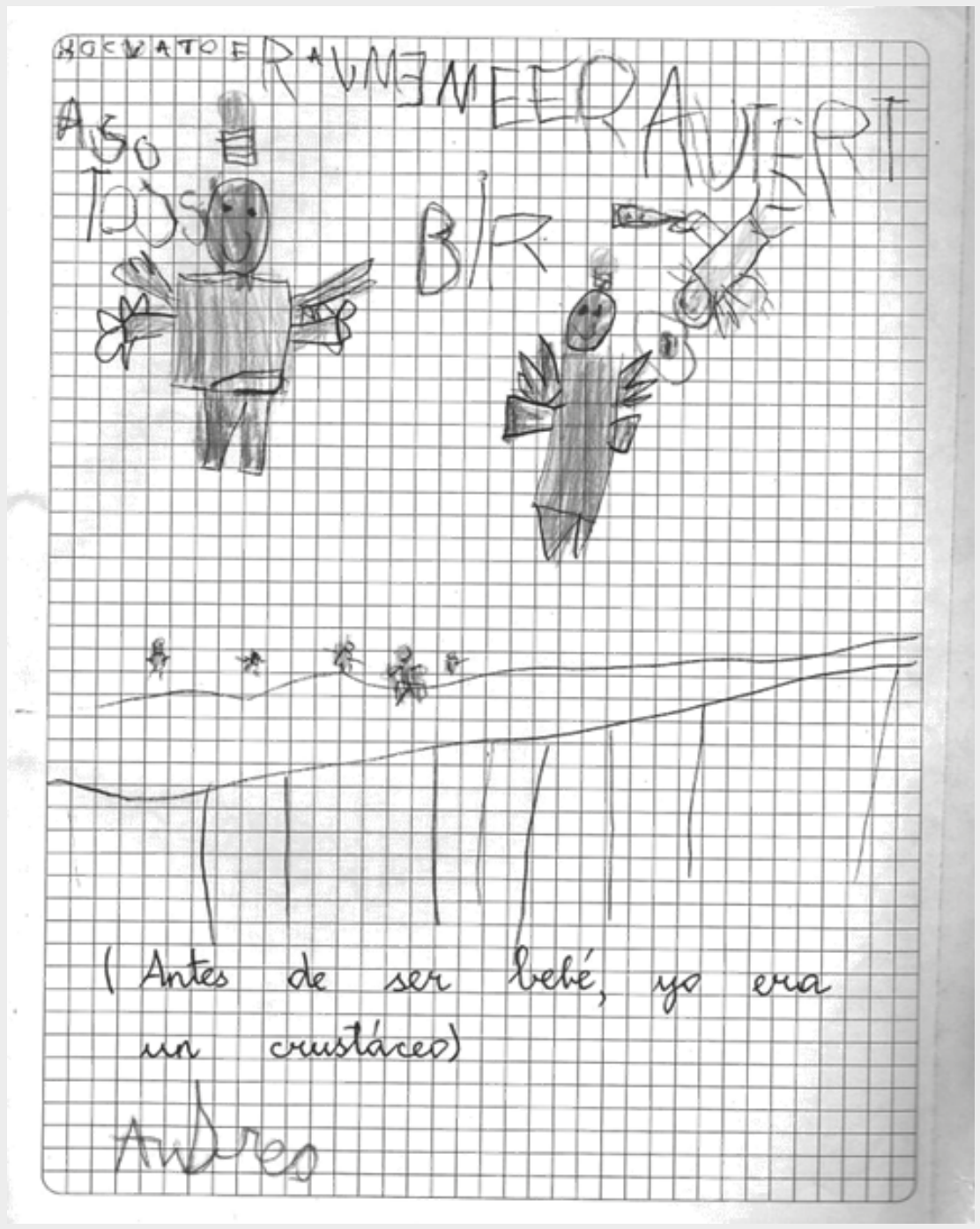

Figura 1. Texto escrito por un niño de 5 años.

En este ejemplo vale la pena detenerse en dos aspectos: por una parte, el número de letras que utiliza el niño para expresar lo que quiere. Son 12, lo que desvirtúa la creencia de que los niños no saben escribir porque no conocen las letras. Por otra parte, es importante detenernos a pensar en lo que implica escribir para este niño: si bien está muy lejos todavía de la convencionalidad, sabe que se escribe para comunicar las ideas, tal como hacen quienes ya hacen parte de una cultura letrada. 


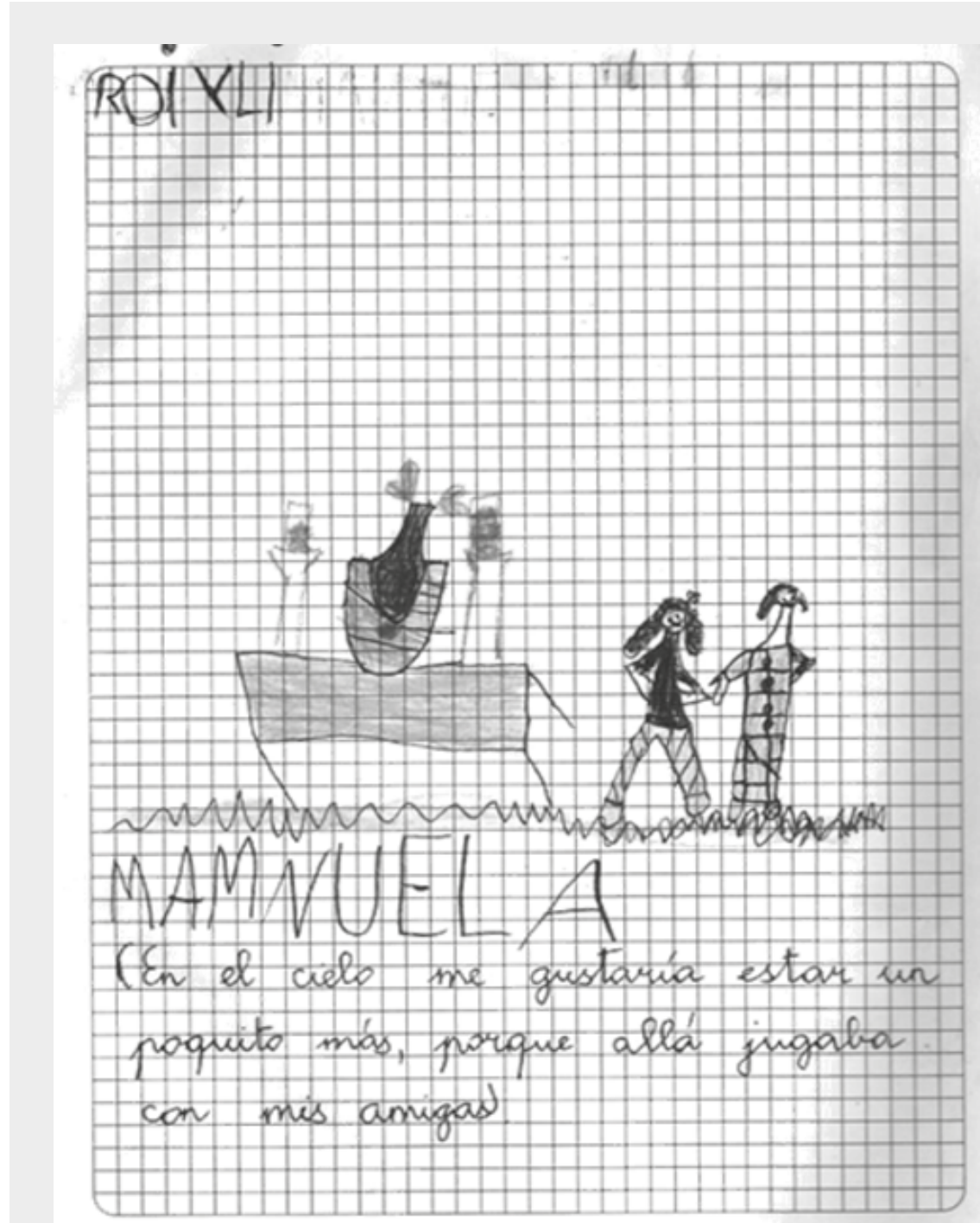

Figura 2. Texto escrito por una niña de 5 años.

Miremos en este otro texto cómo la niña que lo escribe, a pesar de saber escribir casi convencionalmente su nombre, todavía está probando una hipótesis muy inicial respecto a la forma en que funciona el sistema de escritura. Este texto muestra cómo pueden darse procesos simultáneos de aprendizajes memorísticos en la escritura, como es el caso de ser capaz de reproducir su nombre, mientras que el proceso cognitivo va más atrasado. En este caso, el conocimiento de letras es más escaso que en el ejemplo anterior. 


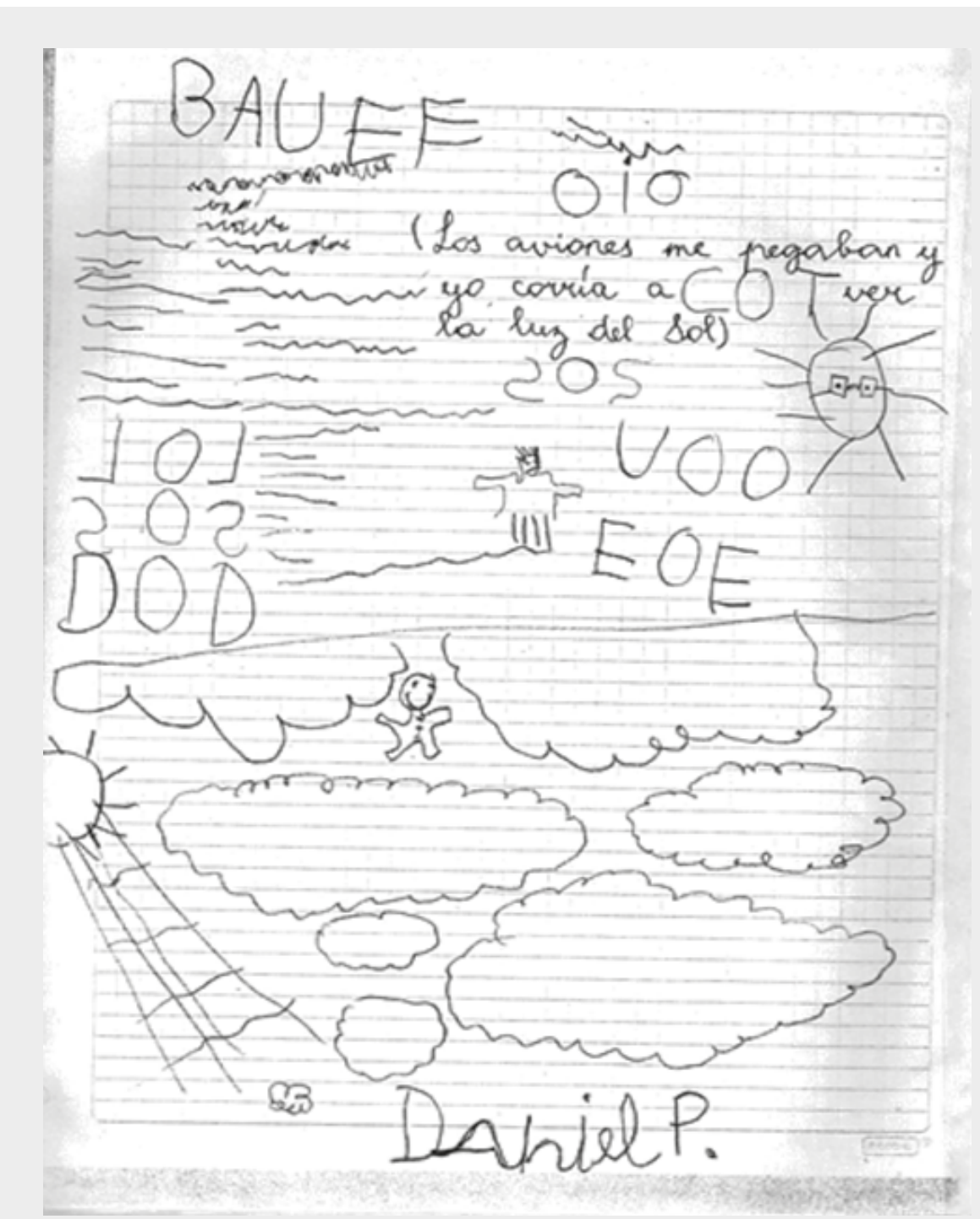

Figura 3. Texto escrito por un niño de 5 años.

En este caso, el pequeño autor inserta letras dentro del dibujo en su texto. Para él todavía no es tan clara la separación entre la representación que se hace por medio del dibujo y la que se hace por medio de las letras. Sin embargo, se evidencian hipótesis de variedad, porque usa diferentes letras para escribir y las combina de diferentes maneras para escribir diferentes letras. Además, pone en práctica la hipótesis de cantidad, porque en ninguna parte usa menos de tres letras para escribir una palabra. Aunque a simple vista parece un proceso incipiente, en él ya se ven hipótesis de alta exigencia cognitiva para escribir. 
Los ejemplos anteriores muestran procesos de largos recorridos que se han iniciado de una manera espontánea en el medio; ningún adulto los ha enseñado a los niños. Sin embargo, ellos, como sujetos activos que son en la construcción de conocimiento, han avanzado en el planteamiento de hipótesis que, bien orientadas, los deben llevar a comprender cómo funciona el sistema de escritura. Pero antes de estos logros, se requiere ayudar a los niños a responder preguntas anteriores sobre el sistema de escritura.

La base de una buena didáctica que facilite la alfabetización inicial está relacionada, entonces, con el conocimiento de diferentes portadores de texto, porque los niños se preguntan en dónde se puede leer, qué se puede leer y para qué se lee. Un portador de texto es "cualquier material impreso o digital, susceptible de ser interpretado" (Guzmán et al., 2018, p. 110). Esto implica que en las aulas haya libros de cuentos que los niños puedan manipular fácilmente, pero también revistas, periódicos y afiches, entre otros materiales, y que los niños puedan preguntar qué dice en cada uno, que los puedan hojear y que puedan jugar “a leer” lo que dicen.

Por otra parte, es importante que puedan seguir formulando hipótesis acerca de cómo se lee y cómo se escribe. En ese sentido, es necesario que el profesor les produzca a los niños situaciones en las que haya un conflicto cognitivo y que los oriente para superarlo. Por ejemplo, cuando un niño hace un intento de escritura, puede preguntarle qué escribió y luego escribirlo debajo correctamente, para preguntarle cuántas letras hay en su escritura y cuántas en la del profesor, cuáles son iguales y cuáles son diferentes, cuáles conoce y otras preguntas que considere pertinentes de acuerdo con cada situación que se presente.

También puede incorporar juegos a su aula para facilitar la alfabetización inicial. Aunque, como afirma Rodríguez (2012, p. 77), “el juego es un concepto nunca agotado, una categoría rica, densa, polémica”, también es cierto que

usar el juego "para otros fines", en este caso, no le quita valor al juego en sí mismo, ya que se constituye en una magnífica oportunidad para propiciar aprendizajes de peso en el marco de la vida social y cultural, así como también para generar un momento grupal grato. (Kispersain y Rodríguez, 2012, p. 65)

Hay muchas posibilidades de incorporar el juego en el aula. Tantas como la creatividad de cada educador permita. De otro lado, cuando los niños empiezan a conocer las letras, preguntan por sus nombres y sonidos; no hay que tener miedo de darles esta información. Eso sí, teniendo claro que no se trata de pretender que se aprendan el abecedario, ni que sepan hacer el trazo de las letras, porque este no es el propósito. La idea es hacerlo tan natural como lo haría un adulto con su hijo, sobrino o nieto en su casa, cuando el niño le pregunta.

En síntesis, se trata de diseñar estrategias de enseñanza que reconozcan los usos sociales de la lectura y la escritura y los dejen entrar al aula para promover avances 
sobre ellos, mediante la relación de los niños con distintos portadores de textos, el disfrute de la lectura de diferentes tipos de textos, el apoyo en la resolución de conflictos cognitivos, la respuesta oportuna a sus preguntas acerca del conocimiento de las letras, la incorporación de juegos al aula y el ingreso de prácticas culturales del entorno respecto a la oralidad, la lectura y la escritura.

¿Por qué la didáctica de la alfabetización inicial tiene relación con la cultura?

Empezamos por plantear que “el lenguaje en sí mismo, marca un hito muy importante en el desarrollo del niño, pero cuando se logra la apropiación del lenguaje escrito, esta posibilidad se amplía gracias a la reflexión que implica el acto de escribir" (Guzmán y Chocontá, 2018, p. 31). Este acto de escribir le permite al niño empezar a reconocerse como miembro de una cultura letrada. La relación de los niños con diferentes símbolos de la cultura, incluidos los escritos, se da desde muy temprano.

En el segundo, tercer y cuarto años de vida el niño pasa de tratar directamente (y de manera exclusiva) con el mundo físico de los objetos (animados e inanimados) a obtener, interpretar y comunicar significados a través de una amplia gama de vehículos simbólicos. (Gardner, 2012, p. 72)

Es necesario entonces que los educadores tengan claro que cuando están diseñando estrategias de enseñanza para los niños, están definiendo de qué maneras van a favorecer su relación con la cultura de la que hacen parte y de otras culturas más amplias: la local, la nacional, la regional y la global. Esto puede suceder en diferentes direcciones: para desconocer la cultura de origen, cuando esta no se toma en cuenta para nada; para menospreciarla cuando no se valora lo que ella aporta; para valorarla y recuperarla, cuando se parte de ella para el diseño de estrategias de enseñanza. Asimismo, mediante la definición de estrategias de enseñanza se puede reducir a los niños exclusivamente a lo local, o bien puede ampliarse hacia otras culturas. Es el educador quien debe tomar las decisiones sobre lo que sucederá en su aula, pero ello demanda conocimiento del medio en que trabaja, del desarrollo infantil, de la importancia de la alfabetización inicial y la posibilidad que existe en la educación inicial de facilitarla, y de las opciones que ofrece a los niños de hacer parte de una cultura letrada para que puedan tener un ejercicio pleno de sus derechos como ciudadanos. No en vano afirma Vigotsky:

Únicamente debemos tratar de imaginar los enormes cambios que se producen en el desarrollo cultural de los niños y que son consecuencia del dominio del lenguaje escrito y de la capacidad de leer. Gracias a ello se accede al conocimiento de todo aquello que el genio humano ha creado en el campo de la palabra escrita. (1979, p. 175)

En la afirmación anterior resalta la importancia que Vigotsky concede al aprendizaje de la escritura dentro de la cultura. Esta idea es apoyada por Rivière (1984), quien plantea que el desarrollo de los niños requiere tomar en cuenta el funcionamiento de su sistema nervioso, pero que este puede ser modificado funcionalmente por la cultura. 
Retomando las ideas anteriores, tendremos que reconocer que la relación de la didáctica con la cultura se da en términos de las posibilidades de desarrollo del funcionamiento del sistema nervioso en un contexto cultural particular, que es el de la escuela, que a su vez hace parte de una sociedad que le ha encomendado el desarrollo de sus miembros más jóvenes, para hacerlos productores de cultura y no solamente consumidores de ella.

Esta posibilidad está muy marcada por lo que haga durante los primeros años, porque, como afirma Mustard (2003, p. 85, citado por Guzmán y Chocontá, 2018, p. 21), “el periodo de desarrollo temprano — que incluye el periodo intrauterino- puede demarcar trayectorias en la salud, el aprendizaje y la conducta e influir en las futuras etapas de desarrollo".

Con esta afirmación podemos volver sobre lo dicho por Peralta (2018), con respecto a que la educación inicial se ha tomado con cierta liviandad. Luego de presentar las relaciones entre la didáctica de la alfabetización inicial, el desarrollo infantil y la cultura, es claro que el trabajo de los educadores de este nivel no se puede agotar en la práctica repetida de actividades solamente porque ellas son "lúdicas", ni en la escogencia de materiales con los que puedan entretener a los niños. La función de un educador del nivel inicial es fundamental en el desarrollo individual y social de los niños, así como en su relación con la cultura.

\section{Referencias}

Ferreiro, E. y Teberosky, A. (1979). Los sistemas de escritura en el desarrollo del niño. México: Siglo XXI.

Ferreiro, E. (2010, octubre 13). DGCyE - Conferencia de la Dra. Emilia Ferreiro (Fragmento IV) (Video). Recuperado de httpps//:www.youtube.com/ watch?v=LvtXrtdSQcO

Flórez Romero, R., Restrepo, M. A. y Schwanenflugel, P (2007). Alfabetismo emergente: investigación, teoría y práctica, el caso de la lectura. Bogotá: Universidad Nacional de Colombia.

Gardner, H. (2012). El desarrollo y la educación de la mente. Barcelona: Paidós.

Guzmán, R. J. y Guevara, M. (2013). El aprendizaje de los educadores sobre los procesos de enseñanza: la alfabetización inicial. Pedagogía y Saberes, (37), 179-189.

Guzmán, R., Ghitis, T. y Ruiz, C. (2018). La lectura y la escritura en los primeros años. Transiciones en el desarrollo y el aprendizaje. Chía, Colombia: Universidad de La Sabana.

Guzmán, R. J. y Chocontá, J. (2018). Desarrollo infantil y escritura. Chía, Colombia: Universidad de La Sabana. 
Kispersain, P. y Rodríguez, I. (2012). El juego como recurso genuino en el aula. En P. M. Sarlé (coord.), Lo importante es jugar: cómo entra el juego en la escuela (pp. 57-73). Rosario, Argentina: Homo Sapiens.

Ministerio de Educación Nacional de Colombia (MEN) (2014). La literatura en la educación inicial. Serie de orientaciones pedagógicas para la educación inicial en el marco de la atención integral. Documento N. ${ }^{0}$ 23. Bogotá: De Cero a siempre. Recuperado de https:/www.mineducacion.gov.co/1759/ articles-341880_archivo_pdf_doc_23.pdf

Peralta, M. (2017). Construyendo currículos posmodernos en la educación inicial latinoamericana. Rosario, Argentina: Homo Sapiens.

Riviére, A. (1984), La psicología de Vigotsky: sobre la larga proyección de una corta biografía. Infancia y Aprendizaje: Journal for the Study of Education and Development, (27-28), 7-86.

Rodríguez, I. (2012). El juego como contenido. En P. M. Sarlé (coord.), Lo importante es jugar: cómo entra el juego en la escuela (pp. 75-88). Rosario, Argentina: Homo Sapiens.

Smith, F. (1983). Comprensión de lectura. Análisis psicolingüístico de la lectura y su aprendizaje. México: Trillas.

Vigotsky, L. (1979). El desarrollo de los procesos psicológicos superiores. Barcelona: Crítica. 